\title{
Is age still valid for segmenting e-shoppers?
}

\author{
Completed Research Paper
}

\author{
Agudo-Peregrina, Ángel F. \\ Universidad Politécnica de Madrid \\ af.agudo@upm.es \\ Acquila-Natale, Emiliano \\ Universidad Politécnica de Madrid \\ emiliano.acquila@upm.es
}

\author{
Hernández-García, Ángel. \\ Universidad Politécnica de Madrid \\ angel.hernandez@upm.es
}

\begin{abstract}
This study examines the differences in the acceptance and use of electronic commerce by end consumers, segmented in three groups according to their age. The UTAUT2 provides the theoretical framework, with the addition of three constructs from e-commerce literature: perceived risk, product risk, and perceived trust. Responses to an online survey by 817 Spanish Internet shoppers validate the research model. An omnibus test of group differences precedes the assessment of four multigroup analysis methods. Results show that gaps caused by age differences in e-shoppers are narrowing. This paper also identifies the strengths and weaknesses of the different multigroup approaches.
\end{abstract}

Keywords: Electronic commerce, acceptance, segmentation, age, multigroup comparison

\section{Introduction}

The use of Partial Least Squares (PLS) to empirically validate relationships in general theoretical models is common in the disciplines of e-business, marketing, and consumer behavior (Henseler et al. 2009). Most of the studies using PLS validate their models from one sample only and assume that this sample is homogeneous. Segmentation is an essential tool for marketing, but it requires analyzing differences between consumers (Kotler \& Armstrong, 2012). Therefore, a homogeneous sample approach is not valid for segmentation. Multigroup analysis allows assessment of these differences across groups in PLS analysis. Some studies use these multigroup methods to analyze different segments and identify significant differences in path estimates (e.g. Agudo-Peregrina et al., 2014.). However, there are still few examples of empirical multigroup analysis, and these examples present two important shortcomings.

First, studies including multigroup analysis limit the empirical validation to the use of only one or at most two methods. Furthermore, studies incorporating two different methods do not perform any comparison between the results from both methods (Henseler et al., 2009). Second, existing PLS multigroup research rarely considers more than two groups in the analysis (e.g. Acedo \& Jones, 2007). In addition, approaches to multigroup analysis with more than two groups focus on pairwise group comparisons, increasing the familywise error rate (Mooi \& Sarstedt, 2011).

Acceptance technology models are good examples of theoretical approaches that rely on 
PLS for empirical validation. The unified theory of acceptance and use of technology (UTAUT) (Venkatesh et al., 2003) is a synthesis of eight previous acceptance models. UTAUT includes moderating variables such as gender, age or experience. In UTAUT and its latter evolution, UTAUT2 (Venkatesh et al., 2012), moderators are dichotomous variables (e.g., male and female users, young and old users, experienced and non-experienced users). However, modeling some moderators - such as age - as dichotomous variables is a too simplistic representation of reality, especially for the study of consumer behavior.

In the case of electronic commerce this oversimplification is particularly relevant, as the use of electronic commerce increases and new consumers from the upper and lower age segments are starting to make online purchases. For example, the number of Internet users in Spain has spiked from $23.5 \%$ in 2000 to $73.1 \%$ of the population (ONTSI, 2014). Meanwhile, online purchasers have increased from $12.7 \%$ in 2000 to $60.6 \%$ in 2013 , with online transactions between consumers and online vendors doubling in less than four years, totaling 14.6 billion euros in 2013 (ONTSI, 2014). In parallel, the characteristics of online consumers have changed and evolved in the last decade. The number of older e-shoppers-more than 49 years old - was $15.2 \%$ of the total in 2007 , but has raised to $21.7 \%$ in 2013 due to the incorporation of new customers and the aging of those that started using electronic commerce in their forties a decade ago. On the other hand, consumers younger than 25 years old are digital natives that have already been born after the emergence of Internet.

This study thereby focuses on the analysis of the impact of consumers' age in the acceptance and use of electronic commerce, and compares the result of applying different multigroup methods with segmentation purposes. The study begins with a review of the ecommerce acceptance literature and the influence of age in e-commerce acceptance in Section 2. Section 3 describes the characteristics of the method. Section 4 shows the data analysis and the results. The final section contains the conclusions and limitations of the study, as well as avenues of future research on this topic.

\section{Literature Review}

\subsection{Electronic commerce acceptance}

Technology acceptance models are theoretical approaches to the study of the factors influencing the adoption of a technology. The first framework to address technology acceptance is the theory of diffusion of innovations (Rogers, 1962), which investigates innovations' characteristics that influence the adoption of a certain technology. Later on, other theoretical models appear in the literature, such as the theory of reasoned action (TRA) (Fishbein \& Ajzen, 1975), the technology acceptance model (TAM) (Davis, 1989), the theory of planned behavior (TPB) (Ajzen, 1991), or the motivational model (Davis, et al. 1992). However, this increase in the number of available models leads to lack of comprehensive perspective. To solve this, Venkatesh et al. (2003) propose a combination of the main eight previous models and formulate UTAUT. UTAUT comprises four main factors affecting behavioral intention to use information systems: effort expectancy, performance expectancy, social influence and facilitating conditions. UTAUT also includes the moderating effects of gender, age, experience, and voluntariness in the acceptance and use of technology. Venkatesh et al. (2012) revise UTAUT and propose UTAUT2. UTAUT2 adds three new factors to the original model - hedonic motivations, habit and price - in order to adapt the model to acceptance and use of technologies by end consumers. 
Despite the absence of prior studies using the UTAUT2 to study the acceptance of electronic commerce, earlier literature confirms the influence of UTAUT factors in purchase intention and purchase behavior (e.g. Pavlou, 2003; Van Slyke et al., 2002). However, among the new predicting variables from UTAUT2, only hedonic motivation is applicable to electronic commerce (Ha \& Stoel, 2009; Morosan \& Jeong, 2008). Consumers do not have to pay a particular fee to purchase online, apart from the Internet connection rate, and therefore price is not relevant. Habit is not a fitting predictor variable either because it has a moderating role instead (Limayem et al., 2007). In addition, literature in e-commerce research proposes two specific factors influencing online purchase intention: perceived risk (Lin et al., 2010; Pavlou, 2003) and perceived trust (Chang, 2010; Chen \& Dhillon, 2003). Bhatnagar and Ghose (2004) further differentiate between two types of perceived risks in online shopping: product risks and system risks.

\subsection{Age as a moderator variable}

Age is a useful segmentation variable in marketing, not only because it is very easy to gather this information from consumers, but also because there are certain socio-cognitive differences between individuals of different ages (Morris \& Venkatesh, 2000). E-commerce literature posits that there are differences in the acceptance and use of online stores contingent on consumers' age. The main results show that younger users have a greater interest on using e-commerce and buy more often (Doolin et al., 2005: Ha \& Stoel, 2009; Joines et al., 2003), and also that the purpose of using e-commerce is different across age groups (Burke, 2002).

Regarding the influence of age as a moderator variable in technology acceptance and ecommerce acceptance, the influence of effort expectancy is stronger for older consumers (Porter \& Donthu, 2006; Venkatesh et al. 2003; Venkatesh et al. 2012; Yu, 2012). The influence of performance expectancy on purchase intention is stronger for young people (Mapeshoane \& Pather, 2012; Teo et al., 2012; Tsai et al., 2013), although some studies state that the influence of performance expectancy is stronger for older consumers because their extrinsic motivations to buy online are higher (Bhatnagar et al, 2000; AbuShanab \& Pearson, 2007). Yu (2012) considers that the impact of social influence in purchase intention is higher in young people, but the study focuses on mobile banking, a service in which young people usually have less experience. Tsai et al. (2013) and AbuShanab and Pearson (2007) also focus on mobile banking, but neither of both studies find that social influence affects purchase intention significantly. For Morris and Venkatesh (2000), the effect of social influence declines with experience, and therefore the effect of social influence on purchase intention might be higher for older consumers. The effect of age on the relation between facilitating conditions and purchase intention (and also purchase behavior) is stronger in the case of older consumers ( $\mathrm{Yu}, 2012)$. The same effect of age is present in the relation between perceived risk and purchase intention (Bhatnagar et al. 2000; Doolin et al. 2005; Liebermann \& Stashavsky, 2002), and perceived trust and purchase intention (Chen \& Dhillon, 2003). However, Bhatnagar and Ghose (2004) consider that product risks have stronger influence on purchase intention for younger customers because the lack of physical contact might increase the perceived risks for those who have less experience identifying the product features. Finally, Bhatnagar et al. (2000) state that the influence of hedonic motivations on purchase intention is stronger for younger consumers. Prior literature does not confirm that age has an effect on the relation between purchase intention and purchase behavior, and therefore purchase intention predicts purchase behavior independently of consumer's age. 
H1. The effect of effort expectancy on purchase intention is higher for older e-consumers.

H2. The effect of performance expectancy on purchase intention is higher for younger econsumers.

H3. The effect of social influence on purchase intention is higher for older e-consumers.

H4. The effect of facilitating conditions on purchase intention is higher for older e-consumers.

H5. The effect of hedonic motivation on purchase intention is higher for younger econsumers.

H6. The effect of perceived trust on purchase intention is higher for older e-consumers.

H7. The effect of system risks on purchase intention is higher for older e-consumers.

H8. The effect of product risks on purchase intention is higher for younger e-consumers.

H9. The effect of facilitating conditions on purchase behavior is higher for older e-consumers.

\section{Method}

According to electronic commerce acceptance literature review, the final research model comprises all factors from UTAUT2 excluding price value and habit, and incorporates three specific factors of electronic commerce: perceived risk (i.e., system risks), product risks and perceived trust. Figure 1 shows the research model.

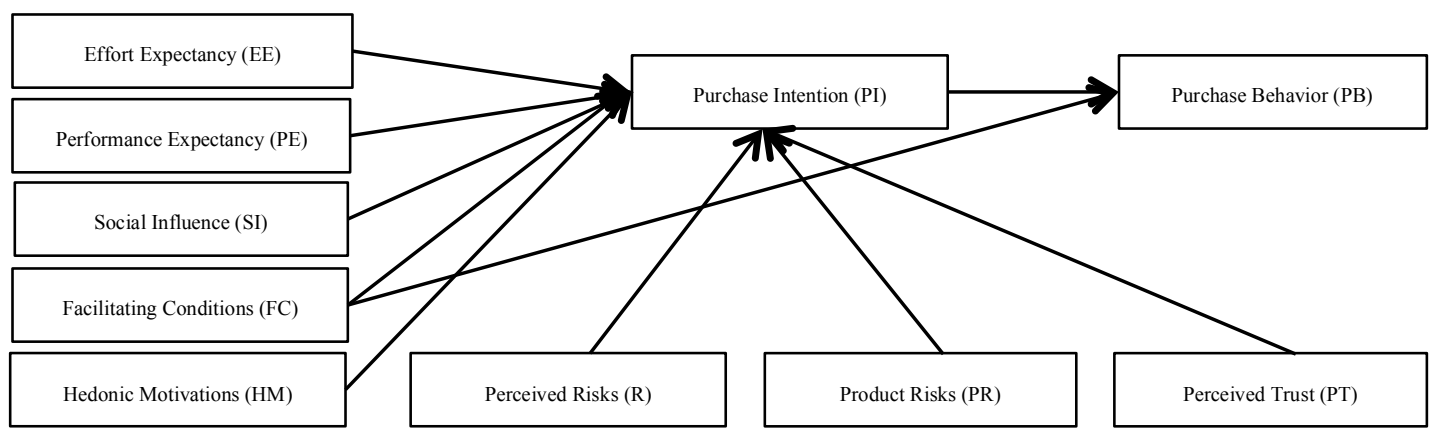

Figure 1: Research model.

\subsection{Participants}

The empirical validation consisted of an online survey that obtained 1,521 total responses from April to October 2013. Most likely because of the questionnaire length (46 items), 704 responses were incomplete and excluded from the final sample, that comprised 817 valid answers. Respondents of the online survey came from announcements to volunteering students at Universidad Politécnica de Madrid, online shoppers from an internal database, posts with links to the questionnaire published in the social networking website LinkedIn, and personal contacts of respondents: a raffle encouraged participants to answer the questionnaire - the prize was a tablet-and also to redistribute the survey in their networks - there was a special prize for the participant that got most referral responses from his or her links.

As shown in Table 1, age divides the sample into three groups. The division of the sample in these three groups responds to historical reasons of the Spanish Internet Access evolution. The senior group - older than 45-, includes those who were at least 30 in 1998, when only one million of Spaniards had Internet connection (Sanz, 2007). Its members were already adult when they used Internet for their first time. Consistently, Spanish statistics show that eshoppers older than 49 represent only $21.7 \%$ of the total population of online buyers, while 
those between 35 and 49 signify 36.4\% (ONTSI, 2014). On the other hand, the junior group contains the e-shoppers younger than 26, that's it, those that where 10 years old at the most in 1998. All three groups are large enough to consider small effect size and high statistical power (Cohen, 1998). According to sample characteristics, experience and frequency in the use of e-commerce of the majority of respondents are very high, with almost no valid participants without experience in online shopping. Table 1 shows the sample characteristics.

Table 1: Sample characteristics

\begin{tabular}{llll}
\hline & & $\mathrm{N}$ & Percentage \\
\hline Gender & Male & 508 & 62.2 \\
& Female & 309 & 37.8 \\
\hline & Under 26 & 181 & 22.1 \\
& $26-45$ & 489 & 59.9 \\
& Over 45 & 147 & 18.0 \\
\hline Monthly income & Less than 500€ & 180 & 22.0 \\
& 500€-1500€ & 243 & 29.8 \\
& 1501€-2000€ & 161 & 19.7 \\
& More than 2000€ & 233 & 28.5 \\
\hline Level of studies & Non university & 101 & 12.3 \\
& University & 511 & 62.6 \\
& Postgraduate & 205 & 25.1 \\
\hline \multirow{4}{*}{ Experience in the use of e- } & Never & 29 & 3.6 \\
commerce & Several weeks & 9 & 1.1 \\
& Several months & 31 & 3.8 \\
& 1 year & 137 & 16.7 \\
& 5 years & 438 & 53.6 \\
& 10 years & 98 & 12.0 \\
& More than 10 years & 75 & 9.2 \\
\hline Frequency in the use of e- & Never & 31 & 3.8 \\
commerce (last six months) & Once & 51 & 6.2 \\
& 2-5 times & 307 & 37.6 \\
& Once a month & 316 & 38.7 \\
& Once a week & 86 & 10.5 \\
& More than once a week & 26 & 3.2 \\
\hline
\end{tabular}

\subsection{Measures}

The final survey included 46 items adapted from UTAUT, UTAUT2, and other ecommerce adoption studies: effort expectancy (4 items), performance expectancy (5 items), social influence ( 2 items), facilitating conditions ( 7 items), hedonic motivations (3 items), product risk (5 items), perceived risk ( 7 items), perceived trust ( 9 items), purchase intention ( 2 items), and actual purchase behavior ( 2 items).

The formulation of the questionnaire items took place in three steps: (1) translation into Spanish; (2) validation by a group of technology management researchers and professors from Universidad Politécnica de Madrid; and (3) item rewording proposal, followed by a face-to-face interview with a random group of 10 students who completed the questionnaire and gave feedback on items to ensure that the questions were clear and understandable. The scale for all items was a Likert-type seven-point scale, ranging from 1 (completely disagree) to 7 (completely agree). The online questionnaire consisted of 46 items in 3 sets: demographic items, non-product-related items, and product-related items. For each respondent, items within each set appeared in a random order to avoid potential response sets.

\subsection{Data analysis}


Considering that no prior studies combine factors from UTAUT and UTAUT2 to study online shopping behavior, and there are both formative (purchase behavior) and reflective constructs (the rest of latent variables), the exploratory aim of the research leads to a traditional partial least squares structural equation modeling (PLS-SEM). PLS-SEM is suitable for analyzing complex models with predictive purposes (Chin, 1998). The statistical analysis tools were XLStat-PLSPM and SmartPLS 3.0 (Ringle et al., 2014).

The analysis of age's moderating effect first validates every model and then develops a multigroup analysis (Sarstedt et al., 2011) with age as a categorical variable (Henseler \& Fassott, 2010) to split the sample in three subsamples. The multigroup analysis included five methods: (1) omnibus test of group differences (OTG) (Sarstedt et al., 2011); (2) a parametric approach assuming equal variances (Chin, 2000); (3) a parametric approach assuming unequal variances (Sarstedt et al., 2011); (4) a non-parametric approach based on permutations (Chin \& Dibbern, 2010); and (5) Henseler et al.'s (2009) PLS multigroup analysis.

\section{Results}

\subsection{Measurement model and structural model}

Measurement model analysis has to ensure validity and reliability requirements for each subsample (e.g. Chin, 1998; Henseler et al., 2009; Hair et al., 2012; Roldan \& SánchezFranco, 2012). Item reliability demands removing items with factorial loadings lower than 0.5 in all three models to guarantee configuration invariance for multigroup analysis (Steenkamp $\&$ Hofstede, 2002). The analysis reveals four invalid items: three indicators from facilitating conditions-FC1 ("I have control over the whole Internet shopping process"); FC6 ("When I shop on the Internet, there is someone who can help me if I experience trouble using the system"); and FC7 ("There is a support line available in the Internet shopping process") - and one item from perceived risks-R7 ("When I shop on the Internet, I risk not finding the lowest prices"). Factorial loadings of most of the remaining items are higher than 0.707. Cronbach's alphas and composite reliabilities are higher than 0.8 for all constructs (Fornell \& Larcker, 1981). The analyses also discarded multicollinearity in the case of the formative construct (PB), with variance inflation factor (VIF) values lower than 5 (Kleinbaum, Kupper \& Muller, 1988).

Convergent validity analysis shows that average variance extracted (AVE) is higher than 0.5 for all constructs, and both Fornell and Larcker (1981) criterion and cross-loadings (Chin, 1998) confirm discriminant validity in all cases. The HTMT criterion (Henseler et al., 2015) shows that values are always lower than 0.85 except between performance expectancy and effort expectancy, with values of $0.91 ; 0.90$; and 0.82 for the Under 25, 26-45, and Over 45 groups, respectively, which slightly violates the $\mathrm{HTMT}_{90}$ criteria in the first two groups.

Table 3 shows the results of the structural model analysis. A bootstrapping procedure with 1000 resamples confirms the structural model's reliability. The bootstrapping procedure with a number of resamples high enough (1000) serves to calculate standard errors and values of the t-statistic for a one-tailed distribution, $\mathrm{t}$ (999) (Chin, 1998).

Table 2: Results of the Structural Model

\begin{tabular}{llll}
\hline & \multicolumn{3}{l}{ Path coefficients for each age segment } \\
\hline Relation & Under 25 & $26-45$ & Over 45 \\
\hline Effort expectancy $\rightarrow$ Purchase intention & 0.038 & $\mathbf{0 . 1 3 8}^{* * *}$ & 0.028 \\
\hline
\end{tabular}




\begin{tabular}{|c|c|c|c|}
\hline Performance expectancy $\rightarrow$ Purchase intention & 0.092 & $0.143^{2, k}$ & $0.274^{* * 2}$ \\
\hline Social influence $\rightarrow$ Purchase intention & 0.022 & 0.044 & 0.065 \\
\hline Facilitating conditions $\rightarrow$ Purchase intention & $0.249^{k \times k \pi}$ & 0.138 & $0.401^{* 2 \pi k \pi}$ \\
\hline Hedonic motivation $\rightarrow$ Purchase intention & 0.059 & $0.103^{* * * k}$ & 0.026 \\
\hline Perceived trust $\rightarrow$ Purchase intention & $0.247^{* * *}$ & $0.171^{* * *}$ & -0.040 \\
\hline Perceived risks $\rightarrow$ Purchase intention & $-0.218^{* * * *}$ & $-0.191^{* \cdots \cdots k}$ & $-0.247^{k * k}$ \\
\hline Product risks $\rightarrow$ Purchase intention & 0.119 & -0.006 & 0.062 \\
\hline Facilitating conditions $\rightarrow$ Purchase behavior & 0.042 & $0.098^{* * *}$ & 0.048 \\
\hline Purchase intention $\rightarrow$ Purchase behavior & $0.686^{* x+k}$ & $0.728^{x+k i k}$ & 0.750 \\
\hline \multicolumn{4}{|l|}{$\mathrm{R}^{2}$} \\
\hline Purchase intention & 0.371 & 0.425 & 0.438 \\
\hline Purchase behavior & 0.497 & 0.595 & 0.603 \\
\hline \multicolumn{4}{|l|}{ 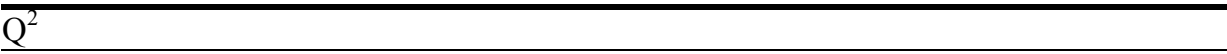 } \\
\hline Purchase intention & 0.287 & 0.374 & 0.334 \\
\hline Purchase behavior & 0.369 & 0.464 & 0.447 \\
\hline \multicolumn{4}{|l|}{ GoF } \\
\hline & 0.545 & 0.610 & 0.626 \\
\hline \multicolumn{4}{|l|}{ SRMR } \\
\hline & 0.064 & 0.050 & 0,073 \\
\hline
\end{tabular}

$* \mathrm{p}<0.05 ; * * \mathrm{p}<0.01 ; * * * \mathrm{p}<0.001 ;$ ns: not significant (based on $\mathrm{t}(999)$, one-tailed test)

$\mathrm{t}(0.05 ; 999)=1.646 ; \mathrm{t}(0.01 ; 999)=2.330 ; \mathrm{t}(0.001 ; 999)=3.098$

Four out of ten relationships are significant in younger and older groups. In the range between 26 and 45 years old, eight out of ten relationships are significant. $\mathrm{R}^{2}$ is higher than 0.1 in all cases (Hair et al., 2012), with a minimum value of 0.371 . Stone-Geisser's $Q^{2}$ confirms the predictive relevance of the relations in all models. Assuming the limitations (Henseler et al., 2009) of the goodness-of-fit index (GoF) (Tenenhaus et al., 2005), GoF values are higher than 0.5 in all models. The composite model SRMR analysis (Henseler et al., 2014) shows that all groups values are lower than the most conservative threshold of 0.08 (Hu and Bentler, 1999).

Facilitating conditions is the main predictor of purchase intention for both the younger and older groups. Perceived risks also have a significant effect on purchase intention, followed by perceived trust for younger consumers, and performance expectancy for older consumers. Perceived risks are the main predictor of purchase intention in the case of the middle-aged adults, followed by perceived trust, performance expectancy, effort expectancy, facilitating conditions and hedonic motivations, all of them exerting a significant effect. Purchase intention is a good predictor of purchase behavior for all groups, with paths higher than 0.65 .

\subsection{Results of the multigroup analysis}

Prior to multigroup analysis, two tests ensure both model and metric invariance of the construct measures. First, all measurement models comprise exactly the same items (42), after removing items with loadings lower than 0.5. All items remaining in the models have loadings higher than 0.5 , and most of them are higher than 0.7 . Second, loadings for every construct should be the same, assuming metric invariance between groups (Chin \& Dibbern, 2010). A permutation-based procedure for multi-group analysis shows that only 6 (under 25 years old vs. 26-45 years old), none (under 25 years old vs. over 45 years old), and 1 (26-45 vs. over 45 years old) of the 42 items are significantly different, representing $14.3 \%, 0 \%$, and $2.4 \%$ of the total, respectively.

Assuming metric invariance according to previous results (Henseler, 2011), the analysis continues with the multi-group tests, that comprises two main steps: OTG and pairwise group 
comparisons. OTG (Sarstedt et al., 2011) assesses whether the null hypothesis that path coefficients are equal across the three groups can be rejected. $F_{R}$ values in Table 4 confirm at least one significant difference between segments for every relationship of the model.

Table 3: Results of the OTG analysis

\begin{tabular}{ll}
\hline Relation & $\mathrm{F}_{\mathrm{R}}$ \\
\hline Effort expectancy $\rightarrow$ Purchase intention & 974.84 \\
\hline Performance expectancy $\rightarrow$ Purchase intention & 1537.51 \\
\hline Social influence $\rightarrow$ Purchase intention & 10939.12 \\
\hline Facilitating conditions $\rightarrow$ Purchase intention & 129.54 \\
\hline Hedonic motivation $\rightarrow$ Purchase intention & 1833.85 \\
\hline Perceived trust $\rightarrow$ Purchase intention & 3939.54 \\
\hline Perceived risks $\rightarrow$ Purchase intention & 5049.00 \\
\hline Product risks $\rightarrow$ Purchase intention & 14339.77 \\
\hline Facilitating conditions $\rightarrow$ Purchase behavior & 700.70 \\
\hline Purchase intention $\rightarrow$ Purchase behavior & 425.22 \\
\hline
\end{tabular}

Pairwise group comparisons indicate which groups are significantly different from others for every relationship. Multigroup analysis contains two parametric methods and two nonparametric methods (see section 3.3). Table 5 shows the results of the comparisons of the four methods between younger and middle-aged e-shoppers. Path differences are higher or equal to 0.1 only in effort expectancy-purchase intention, facilitating conditions-purchase intention and product risks-purchase intention relationships. Three of the four methods - permutations being the exception - consider that there is a significant difference in the relationship between product risks and purchase intention, and only two of the four methods-parametric nonequivalent variances and Henseler-indicate that there is significant difference in the relationship between facilitating conditions and purchase intention.

Table 4: Results of the multi-group analysis (between under 25 years old and 26-45 years old)

\begin{tabular}{llllll}
\hline Relation & Diff & $\mathrm{t}_{\text {par-eq }}$ & $\mathrm{t}_{\text {par-non eq }}$ & $\mathrm{p}_{\text {perm }}$ & $\mathrm{p}_{\text {Hen }}$ \\
\hline Effort expectancy $\rightarrow$ Purchase intention & $-0,100$ & 1,109 & $-1,402$ & 0,424 & 0,941 \\
\hline Performance expectancy $\rightarrow$ Purchase intention & $-0,051$ & 0,645 & $-0,829$ & 0,675 & 0,797 \\
\hline Social influence $\rightarrow$ Purchase intention & $-0,022$ & 0,457 & $-0,557$ & 0,758 & 0,746 \\
\hline Facilitating conditions $\rightarrow$ Purchase intention & 0,111 & 1,585 & $\mathbf{2 , 0 6 3}$ & 0,287 & $\mathbf{0 , 0 1 8}$ \\
\hline Hedonic motivation $\rightarrow$ Purchase intention & $-0,044$ & 0,883 & $-1,055$ & 0,530 & 0,870 \\
\hline Perceived trust $\rightarrow$ Purchase intention & 0,076 & 1,088 & 1,313 & 0,454 & 0,094 \\
\hline Perceived risks $\rightarrow$ Purchase intention & $-0,027$ & 0,428 & $-0,524$ & 0,770 & 0,703 \\
\hline Product risks $\rightarrow$ Purchase intention & 0,125 & $\mathbf{2 , 1 0 9 *}$ & $\mathbf{2 , 4 8 9}{ }^{* *}$ & 0,144 & $\mathbf{0 , 0 0 0}{ }^{* * *}$ \\
\hline Facilitating conditions $\rightarrow$ Purchase behavior & $-0,056$ & 0,312 & $-0,383$ & 0,820 & 0,657 \\
\hline Purchase intention $\rightarrow$ Purchase behavior & $-0,042$ & 1,012 & $-1,253$ & 0,478 & 0,891 \\
\hline$<0.05 ; * p<0.01 ; * *$ p $<0.001$ & & & & &
\end{tabular}

Table 6 summarizes the results of an analogous multigroup analysis for the comparisons between younger and older e-shoppers (under 25 years old vs. over 45 years old), and between middle-aged and older e-shoppers (26-45 years old vs. over 45 years old). Table 6 shows the differences between path estimates and a letter indicating the number of methods that showed significant differences.

Table 5: Results of the multigroup analysis and hypotheses testing \begin{tabular}{llllll}
\hline Relation & $<25$ vs. $26-45$ & $<25$ vs. $>45$ & $26-45$ vs. $>45$ & Hyp. & Supported? \\
\hline
\end{tabular} 


\begin{tabular}{llllll}
\hline Effort expectancy $\rightarrow$ Purchase intention & $-0.1^{\mathrm{e}}$ & $0.01^{\mathrm{e}}$ & $0.11^{\mathrm{d}}$ & H1 & No \\
\hline Performance expectancy $\rightarrow$ Purchase intention & $-0.051^{\mathrm{e}}$ & $\mathbf{- 0 . 1 8 2}^{\mathbf{b}}$ & $-0.131^{\mathrm{c}}$ & H2 & No \\
\hline Social influence $\rightarrow$ Purchase intention & $-0.022^{\mathrm{e}}$ & $-0.043^{\mathrm{e}}$ & $-0.021^{\mathrm{e}}$ & H3 & No \\
\hline Facilitating conditions $\rightarrow$ Purchase intention & $0.111^{\mathrm{c}}$ & $\mathbf{- 0 . 1 5 2}^{\mathbf{b}}$ & $\mathbf{- 0 . 2 6 3}^{\mathbf{a}}$ & H4 & Partially \\
\hline Hedonic motivation $\rightarrow$ Purchase intention & $-0.044^{\mathrm{e}}$ & $0.033^{\mathrm{e}}$ & $0.077^{\mathrm{c}}$ & H5 & No \\
\hline Perceived trust $\rightarrow$ Purchase intention & $0.076^{\mathrm{e}}$ & $\mathbf{0 . 2 8 7}^{\mathrm{a}}$ & $\mathbf{0 . 2 1 1}^{\mathbf{b}}$ & H6 & No \\
\hline Perceived risks $\rightarrow$ Purchase intention & $-0.027^{\mathrm{e}}$ & $0.029^{\mathrm{e}}$ & $0.056^{\mathrm{e}}$ & H7 & No \\
\hline Product risks $\rightarrow$ Purchase intention & $\mathbf{0 . 1 2 5}^{\mathbf{b}}$ & $0.057^{\mathrm{e}}$ & $-0.068^{\mathrm{d}}$ & H8 & No \\
\hline Facilitating conditions $\rightarrow$ Purchase behavior & $-0.056^{\mathrm{e}}$ & $-0.006^{\mathrm{e}}$ & $-0.05^{\mathrm{e}}$ & H9 & No \\
\hline Purchase intention $\rightarrow$ Purchase behavior & $-0.042^{\mathrm{e}}$ & $-0.064^{\mathrm{e}}$ & $-0.022^{\mathrm{e}}$ & &
\end{tabular}

Significant differences in: ${ }^{\mathrm{a}}$ Four methods; ${ }^{\mathrm{b}}$ Three methods; ${ }^{\mathrm{c}}$ Two methods; ${ }^{\mathrm{d}}$ One method; ${ }^{\mathrm{e}}$ None.

From the results, the four methods consider that the differences are significant only for facilitating conditions-purchase intention and perceived trust-purchase intention relations. In all cases marked as ${ }^{b}$, permutations is the method for which the difference is not significant. Similarly, by observing the cases noted as ${ }^{\mathrm{c}}$, the most restrictive methods are permutations and the parametric approach assuming equivalent variances. Nonetheless, the p-values of the latter are just slightly above 0.05 . Henseler et al.'s (2009) procedure is the least restrictive because it is the only method that finds significant differences in the cases noted as ${ }^{\mathrm{d}}$.

From Table 6, hypotheses 1,3,5, 7 and 9 are not supported because there are no significant differences across groups. Hypothesis 2 is not supported either because performance expectancy is higher for older e-shoppers. Hypothesis 4 is only partially supported because, even though all differences are significant, the effect of facilitating conditions on purchase behavior is higher for younger e-shoppers than for middle-aged e-shoppers. Hypothesis 6 is not supported because the influence of perceived trust is higher for younger consumers. Lastly, hypothesis 8 is not supported because none of the paths are significant for any group.

\section{Conclusions}

This study analyzes the differences in the acceptance and use of e-commerce between segments of electronic consumers belonging to groups of different ages. The multigroup analyses comprise five methods that report different results. Surprisingly, none of the hypotheses are fully supported, and only one is partially supported.

The study contributes to theory by validating UTAUT2 in an e-commerce context. The findings from the empirical analysis suggest that age may not be moderating the relation between predictors and e-shopping behavior. This might invalidate its relevance as segmentation variable for online shopping. It appears that, once the older e-shoppers overcome the barriers to online shopping, the differences with younger consumers disappear. Nevertheless, online retailers can take advantage of the findings from this study, by adapting their marketing strategies according to the differences in the factors that predict purchase intention in every segment. Furthermore, regardless of consumers' age, retailers should lower risk perceptions and avoid interferences in the purchasing process so that consumers do not perceive that they are not in control of the process. This recommendation is particularly important in the case of older shoppers. On the other side, increasing the perception of trust (e.g. using social networks to keep a direct contact with customers) might be consistent with young consumers' needs.

Methodologically, the results of the analysis suggest that OTG is a less restrictive method, considering that OTG detects significant differences that none of the other methods detect between any of the groups. Further research should include OTG in multigroup analysis of 
more than two groups to confirm the results from this study. The analyses also find that apparently both parametric approaches behave similarly, but non-parametric methods in general show opposite results, with permutations being very restrictive and Henseler et al.'s (2009) method being very permissive.

While most of the respondents have previous experience with online shopping, this research lacks perspective from non-shoppers. This limitation of the sample might affect generalization of results about the moderating effect of age from this study. A broader study should consider completing the sample with non-experienced (or at least with limited eshopping experience) participants. Finally, future research should further explore the wellestablished measures for effort expectancy and performance expectancy, based on the results of the HTMT method - note that the original study only used the traditional discriminant validity assessment methods available in previous PLS-SEM analysis software packages.

\section{References}

AbuShanab, E., \& Pearson, J. M. (2007). Internet banking in Jordan. The Unified theory of acceptance and use of technology (UTAUT) perspective. Journal of Systems and Information Technology, 9(1), 78-97.

Acedo, F. J., \& Jones, M. V. (2007). Speed of internationalization and entrepreneurial cognition: Insights and a comparison between international new ventures, exporters and domestic firms. Journal of World Business, 42(3), 236-252.

Agudo-Peregrina, Á. F., Pascual-Miguel, F. J., \& Chaparro-Peláez, J. (2014). It's never the same: the role of homogeneity in online services. Service Business, 8(3), 453-464.

Ajzen, I. (1991). The theory of planned behavior. Organizational Behavior and Human Decision Processes, 50(2), 179-211.

Bhatnagar, A., \& Ghose, S. (2004). Segmenting consumers based on the benefits and risks of Internet shopping. Journal of Business Research, 57(12), 1352-1360.

Bhatnagar, A., Misra, S., \& Rao, H. R. (2000). On Risk, Convenience , and Internet Shopping Behavior. Communications of the ACM, 43(11), 98-105.

Burke, R. R. (2002). Technology and the Customer Interface: What Consumers Want in the Physical and Virtual Store. Journal of the Academy of Marketing Science, 30(4), 411432.

Chang, H. H. (2010). Task-technology fit and user acceptance of online auction. International Journal of Human-Computer Studies, 68(1-2), 69-89.

Chen, S. C., \& Dhillon, G. S. (2003). Interpreting dimensions of consumer trust in ecommerce. Information Technology and Management, 4(2-3), 303-318.

Chin, W. W. (1998). The partial least squares approach to structural equation modelling. In $G$. A. Marcoulides (Ed.), Modern methods for business research. (Vol. 8, pp. 295-336). Mahwah, NJ: Lawrence Erlbaum Associates, Inc.

Chin, W. W. (2000). Frequently Asked Questions - Partial Least Squares \& PLS-Graph. Home Page. [On-line]. Retrieved from Available: http://discnt.cba.uh.edu/chin/plsfaq.htm

Chin, W. W., \& Dibbern, J. (2010). An Introduction to a Permutation Based Procedure for Multi-Group PLS Analysis: Results of Tests of Differences on Simulated Data and a Cross Cultural Analysis of the Sourcing of Information System Services Between Germany and the USA, In Handbook of Partial Least Squares, Esposito Vinzi, V., Chin, W. W., Henseler, J., \& Wang,H. Eds. (pp. 713-735). Springer Berlin Heidelberg. Cohen, J. (1988). Statistical power analysis for the behavioral sciences. (Department of 
Psychology. University of New York, Ed.). New York: Routledge.

Davis, F. D. (1989). Perceived usefulness, perceived ease of use, and user acceptance of information technology. MIS Quarterly, 13(3), 319-340.

Davis, F. D, Bagozzi, R. P., \& Warshaw, P. R. (1992). Extrinsic and intrinsic motivation to use computers in the workplace. Journal of Applied Social Psychology, 22(14), 11111132 .

Doolin, B., Dillon, S., Thompson, F., \& Corner, J. L. (2005). Perceived risk, the Internet shopping experience and online purchasing behavior: A New Zealand perspective. Journal of Global Information Management, 13(2), 66-88.

Fishbein, M., \& Ajzen, I. (1975). Belief, attitude, intention, and behavior: An introduction to theory and research. MA: Addison-Wesley.

Fornell, C., \& Larcker, D. F. (1981). Structural equation models with unobservable variables and measurement error: Algebra and statistics. Journal of marketing research, 18, 382-388.

Ha, S., \& Stoel, L. (2009). Consumer e-shopping acceptance: Antecedents in a technology acceptance model. Journal of Business Research, 62(5), 565-571.

Hair, J. F., Sarstedt, M., Ringle, C. M., \& Mena, J. A. (2012). An assessment of the use of partial least squares structural equation modeling in marketing research. Journal of the Academy of Marketing Science, 40(3), 414-433.

Henseler, J. (2011) Recent Advances in PLS Path Modeling. Analyzing Interaction Effects and Multiple Groups, University of Seville, October 28, 2011.

Henseler, J., Dijkstra, T. K., Sarstedt, M., Ringle, C. M., Diamantopoulos, A., Straub, D. W., Ketchen, D. J., Hair, J. F., Hult, G. T. M., and Calantone, R. J. 2014. Common Beliefs and Reality about Partial Least Squares: Comments on Rönkkö \& Evermann (2013), Organizational Research Methods 17(2): 182-209.

Henseler, J. \& Fassott, G. (2010) Testing Moderating Effects in PLS Path Models: An Illustration of Available Procedures, In Handbook of Partial Least Squares, Esposito Vinzi, V., Chin, W. W., Henseler, J., \& Wang,H. Eds. (pp. 713-735). Springer Berlin Heidelberg.

Henseler, J., Ringle, C. M., \& Sarstedt, M. (2015). A new criterion for assessing discriminant validity in variance-based structural equation modeling. Journal of the Academy of Marketing Science, 43(1), 115-135.

Henseler, J., Ringle, C. M., \& Sinkovics, R. R. (2009). The use of partial least squares path modeling in international marketing. Advances in International Marketing, 20, 277320.

Hu, L.-t., and Bentler, P. M. 1998. Fit Indices in Covariance Structure Modeling: Sensitivity to Underparameterized Model Misspecification, Psychological Methods 3(4): 424453.

Joines, J. L., Scherer, C. W., \& Scheufele, D. A. (2003). Exploring motivations for consumer Web use and their implications for e-commerce. Journal of Consumer Marketing, 20(2), 90-108.

Kleinbaum, D.G., Kupper, L.L. \& Muller, K.E. (1988) Applied Regression Analysis and other Multivariate Analysis Methods. Boston, PWS-Kent Publishing Company.

Kotler, P., \& Armstrong, G. (2012). Principles of Marketing. 14th Edition (pp. 1-740).

Liebermann, Y., \& Stashevsky, S. (2002). Perceived risks as barriers to Internet and ecommerce usage. Qualitative Market Research: An International Journal, 5(4), 291300 .

Lin, W. B., Wang, M. K., \& Hwang, K. P. (2010). The combined model of influencing online consumer behavior. Expert Systems with Applications, 37(4), 3236-3247.

Limayem, M., Hirt, S. G., \& Cheung, C. M. K. (2007). How habit limits the predictive power 
of intentions: The case of IS continuance. MIS Quarterly, 31(4), 705-737.

Mapeshoane, T. J., \& Pather, S. (2012). Adoption of e-commerce in typical developing country context: Lesotho tourism industry. Proceedings of the 14th Annual Conference on World Wide Web Applications Durban, (pp. 7-9).

Morosan, C., \& Jeong, M. (2008). Users' perceptions of two types of hotel reservation web sites. International Journal of Hospitality Management, 27(2), 284-292.

Morris, M. G., \& Venkatesh, V. (2000). Age differences in technology adoption decisions: implications for a changing work force. Personnel Psychology, 53(2), 375-403.

Mooi, E. A., \& Sarstedt, M. (2011). A concise guide to market research: The process, data, and methods using IBM SPSS statistics. Berlin: Springer.

ONTSI. (2014). Study of the B2C Electronic Commerce 2013. Edition 2014. Madrid: ONTSI.

Pavlou, P. A. (2003). Consumer acceptance of electronic commerce: Integrating trust and risk with the technology acceptance model. International Journal of Electronic Commerce, $7(3), 101-134$.

Porter, C. E., \& Donthu, N. (2006). Using the technology acceptance model to explain how attitudes determine Internet usage: The role of perceived access barriers and demographics. Journal of Business Research, 59(9), 999-1007.

Sanz, M.A. (2007). Fundamentos históricos de la Internet en Europa y en España. Boletín de Red IRIS, 44, 22-36.

Ringle, C.M., Wende, S., \& Will, A. (2014). SmartPLS 3.0. Germany: University of Hamburg.

Roldán, J. L., \& Sánchez-Franco, M. J. (2012). Variance-Based Structural Equation Modeling: Guidelines for Using Partial Least Squares in Information Systems Research. En M. Mora, O. Gelman, A. Steenkamp, \& M. Raisinghani (eds), Research Methodologies, Innovations and Philosophies in Software Systems Engineering and Information Systems, pp. 193-221. Hershey PA: Information Science Reference.

Rogers, E. M. (1962). Diffusion of Innovations (1st Edition). The Free Press.

Sarstedt, M., Henseler, J., \& Ringle, C. M. (2011). Multigroup Analysis in Partial Least Squares (PLS) Path Modeling: Alternative Methods and Empirical Results. In Measurement and Research Methods in International Marketing (Advances in International Marketing, Volume 22) (Vol. 22, pp. 195-218). Bingley: Emerald Group Publishing Limited.

Steenkamp, J. B. E., \& Hofstede, F. T. (2002). International market segmentation: issues and perspectives. International Journal of Research in Marketing, 19(3), 185-213.

Tenenhaus, M., Esposito Vinzi, V., Chatelin, Y.M., \& Lauro, C. (2005). PLS path modeling. Computational Statistics \& Data Analysis, 48 (1), 159-205.

Teo, T. S., \& Liu, J. (2007). Consumer trust in e-commerce in the United States, Singapore and China. Omega, 35(1), 22-38.

Tsai, C. H., Zhu, D. S., \& Jang, Y. M. (2013). A study on the consumer adoption behaviors of Internet Bank. In 2013 IEEE/ACIS 12th International Conference on Computer and Information Science (ICIS) (pp. 263-268).

Van Slyke, C., Comunale, C. L., \& Belanger, F. (2002). Gender differences in perceptions of web-based shopping. Communications of the ACM, 45(8), 82-86.

Venkatesh, V., Morris, M. G., Davis, G. B., \& Davis, F. D. (2003). User acceptance of information technology: Toward a unified view. MIS Quarterly, 27(3), 425-478.

Venkatesh, V., Thong, J. Y. L., \& Xu, X. (2012). Consumer acceptance and use of information technology: Extending the unified theory of acceptance and use of technology. MIS Quarterly, 36(1), 157-178.

$\mathrm{Yu}, \mathrm{C}$. S. (2012). Factors Afecting Individuals to Adopt Mobile Banking: Emprical Evidence from the UTAUT Model. Journal of Electronic Commerce Research, 13(2), 104-121. 